\title{
EVALUATION OF KITE AND PONSETI METHODS IN THE TREATMENT OF IDIOPATHIC CONGENITAL CLUBFOOT
}

\section{AVALIAÇÃO DOS MÉTODOS DE KITE E DE PONSETI NO TRATAMENTO DO PÉ TORTO CONGÊNITO IDIOPÁTICO}

\author{
Lucas Cortizo Garcia ${ }^{1}$, lucas Rocha de Jesus ${ }^{1}$, Mateus de Oliveira Trindade ${ }^{2}$, Fernando Cal Garcia Filho², Magda Leão Pinheiro ${ }^{3}$, \\ Rafaela Jucá Píres de Sá⿱2
}

1. Centro Ortopédico Traumatológico (COT), Salvador, BA, Brazil.

2. Hospital Martagão Gesteira, Salvador, BA, Brazil.

3. Medicine Scholar, Faculdade de Tecnologia e Ciência (FTC), Salvador, BA, Brazil.

\section{ABSTRACT}

Objective: Clubfoot is one of the most common congenital deformities affecting the musculoskeletal system. The main conservative treatment for clubfoot includes the Ponseti's and Kite's methods. This study aimed to perform a comparative evaluation of the effectiveness of the Ponseti and Kite approaches for the conservative treatment of clubfoot. Methods: One hundred children with clubfoot abnormality, visiting the Martagão Gesteira Hospital, were divided in two groups. The first group received conservative treatment using the Kite method and the second group received conservative treatment using the Ponseti method. At the end of the treatment, both groups were evaluated based on the Pirani classification to verify whether there had been an adequate correction of the deformity. The variables studied included correction of deformity, age, sex, and laterality. Results: The effectiveness of the Kite and Ponseti methods of conservative treatment showed significant statistical differences. Conclusion: The present study shows that the efficacy of conservative treatment using the Ponseti method was $18 \%$ higher than that of the Kite method. Level of evidence II, randomized clinical trial.

Keywords: Clubfoot. Conservative Treatment. Orthopedics.

\section{RESUMO}

Objetivo: O Pé Torto Congênito Idiopático (PTC I) é um dos defeitos congênitos mais comuns, que envolvem o sistema músculo-esquelético, cujos principais tratamentos conservadores são através do método de Kite e de Ponseti. A presente pesquisa busca uma avaliação comparativa da eficácia dos métodos de Ponseti e de Kite, no tratamento conservador do PTC I. Metodologia: Foram tratadas 100 crianças portadoras da deformidade do PTC I, no Hospital Infantil Martagão Gesteira, sendo divididas em dois grupos. No primeiro grupo foi instituído o tratamento conservador pelo método de Kite e no segundo grupo foi instituído o tratamento conservador pelo método de Ponseti. Ao final do tratamento, ambos os grupos foram avaliados com base na classificação de Pirani para verificar se houve correção adequada da deformidade. Foram estudadas as variáveis de correção da deformidade, idade, sexo e lateralidade. Resultados: Houve diferença estatisticamente significante entre os métodos de tratamento conservador de Kite e de Ponseti. Conclusão: O presente estudo demonstrou que a eficácia do tratamento conservador pelo método de Ponseti foi superior em 18\% em relação ao método do Kite. Nível de evidência II, ensaio clínico randomizado.

Descritores: Pé torto Equinovaro. Tratamento Conservador. Ortopedia.

Citation: Garcia LC, Jesus LR, Trindade MO, Garcia Filho FC, Pinheiro ML, Sá RJP. Evaluation of kite and ponseti methods in the treatment of idiopathic congenital clubfoot. Acta Ortop Bras. [online]. 2018;26(6):366-9. Available from URL: http://www.scielo.br/aob.

\section{INTRODUCTION}

Idiopathic congenital talipes equinovarus (ICTEV) may be defined as an inversion deformity characterized by three-dimensional structural deformities such as hindfoot equinus and varus, midfoot cavus, and forefoot adductus. It is present at birth and is one of the most common congenital defects involving the musculoskeletal system. ICTEV is also known as "clubfoot" and "talipes equinovarus" and has a global incidence of one case per 1000 live births, with some influence of genetic and ethnic factors. It is predominant in male patients, with a male:female ratio of 2.5:1. ICTEV is more commonly unilateral, on the right side, but may be present bilaterally in $50 \%$ of cases. When not treated or treated inappropriately, it may cause functional and psychological harm to the child. ${ }^{1,2}$

The first written reports of ICTEV were by Hippocrates, around 400 $\mathrm{BC}$, who described treatment with repeated manual manipulations, without the use of force, followed by immobilization with bandages to maintain the foot in the correct position. Guerin was the first to report the use of a plaster cast in 1836. In the twentieth century, forced corrections were reported with the use of devices such as the Thomas splint. Kite, in 1932, described his method of conservative

All authors declare no potential conflict of interest related to this article. 
management of ICTEV, using smooth and repeated manipulations, followed by cast immobilization. Later, in 1950, Ponseti developed his own technique that also uses manipulations and serial cast immobilizations. ${ }^{2,3}$

The success of both methods mainly depends on the regularity of the cast changes, since the principles of reduction of the dislocated and sub-dislocated articulations of the foot are distinct. Thus, the objective of the present study was to provide criteria to help choose the most effective method of correction for ICTEV.

\section{MATERIALS AND METHODS}

A randomized controlled clinical trial was performed to compare two methods of conservative treatment with serial plaster casting for the correction of ICTEV of level of evidence II. The study was approved by the Ethics Committee of the Instituto Mantenedor do Ensino Superior da Bahia (IMES) under protocol number 56832316400005032. All patients had an informed consent form signed by their legal guardian. Data collection was performed from the follow-up of ICTEV treatment by two conservative methods at the Department of Orthopedics and Traumatology of the Hospital Martagão Gesteira, from January 2012 to May 2013. The patients were divided into two groups according to the different treatment methods (Kite and Ponseti), in which plaster casts were applied weekly for six to ten weeks. At the end of each treatment, the results for each participant were evaluated using the Pirani scoring system that is based on the physical appearance of the deformity during the clinical evaluation of the hindfoot and midfoot.

Procedures for plaster casting and corrective evaluation were performed at the outpatient department of Pediatric Orthopedics Unit of the Martagão Gesteira Hospital, where only a single clinician was responsible for performing such procedures from 2012 to May 2013. The study included infants of both sexes, aged 10 days to 12 months, diagnosed with ICTEV. The choice of treatment method for each patient was based on convenience and on an individual patient basis as either unilateral or bilateral.

The following inclusion and exclusion criteria were considered. Inclusion criteria consisted of patients diagnosed with ICTEV, aged between 10 days and 12 months, exhibiting unilateral or bilateral foot deformities. Exclusion criteria consisted of children without an ICTEV diagnosis, patients with associated underlying pathologies (myelodysplastic, neurological, or arthrogrypotic disorders), patients who were not able to change plaster casts for the Ponseti treatment weekly for socioeconomic reasons, patients whose legal guardian did not sign the informed consent form, and those who had been treated previously for the same pathology using therapeutic techniques other than the Kite and Ponseti methods.

The variables studied were sex, age, laterality of the deformity, and efficacy (correction of deformity) of the treatments.

\section{RESULTS}

A total of 100 children participated in the study; 50 underwent treatment with the Kite method and 50 received treatment with the Ponseti method. The study sample consisted of 58 (58\%) boys and $42(42 \%)$ girls, of which $40(40 \%)$ children presented deformity in the left lower limb, 33 (33\%) in the right lower limb, and 27 (27\%) children presented bilateral deformity (Table 1).

In the Kite group, 38 (76\%) children achieved satisfactory correction following treatment, and for $12(24 \%)$ children, treatment was unsatisfactory. In the Ponseti group, 47 (94\%) children achieved satisfactory correction, while treatment outcome was not satisfactory in $3(6 \%)$ children (Table 2). Significance was calculated using Fisher's Exact Test, where $p=0.023$.
Regarding the laterality of the deformity, in the group submitted to the Kite method that achieved a satisfactory correction, 16 children $(42.1 \%)$ presented with deformity in the left foot, 17 (44.7\%) in the right foot, and 5 children (13.2\%) presented with the deformity in both feet (Table 3).

In the group submitted to treatment by the Ponseti method that achieved satisfactory correction, 14 children (29.8\%) presented with the deformity in the left foot, 12 children (25.5\%) in the right foot, and 21 children (44.7\%) presented with bilateral deformities (Table 4).

Of the patients who achieved correction after treatment with the Kite method, 27 (71\%) were male and 11 (29\%) were female, while of the patients who achieved correction after treatment with the Ponseti method, 24 (51\%) were male and 23 (49\%) were female (Table 5).

Of the patients who achieved correction after treatment with the Kite method, 24 (63.2\%) were aged between 10 to 15 days and 6 months and $14(36.8 \%)$ were aged between 6 months and 1 year. Of the patients who achieved correction after treatment with the Ponseti method, 37 (78.7\%) were aged between 10 to 15 days and 6 months, and 10 (21.27\%) were aged between 6 months and 1 year (Table 6).

\section{DISCUSSION}

The initial treatment for ICTEV is generally conservative; however, reports in the literature are controversial with regard to its indication as there are many different techniques described for manipulation, with treatment success rates ranging from $11 \%$ to $89 \%{ }^{2}$

In 1932, Kite, published a treatment method using manipulation that aimed at the correction of each component of ICTEV separately. First, the adductus was corrected with the abduction of the foot

Table 1. Characteristics of the laterality of the deformity of subjects of the study sample.

\begin{tabular}{c|c|c}
\hline \multicolumn{3}{|c|}{ the study sample. } \\
\hline Left & Right & Bilateral \\
\hline $40(40 \%)$ & $33(33 \%)$ & $27(27 \%)$ \\
\hline
\end{tabular}

Table 2. Correction after treatments by the Kite and Ponseti methods.

\begin{tabular}{c|c|c|c}
\hline Method & Corrected & Not corrected & Total \\
\hline Kite & $38(76 \%)$ & $12(24 \%)$ & 50 \\
\hline Ponseti & $47(94 \%)$ & $3(6 \%)$ & 50 \\
\hline Total & 85 & 15 & 100 \\
\hline
\end{tabular}

Table 3. Laterality of the correction through Kite's conservative method.

\begin{tabular}{c|c|c}
\hline Left & Right & Bilateral \\
\hline $16(42.1 \%)$ & $17(44.7 \%)$ & $5(13.2 \%)$ \\
\hline
\end{tabular}

Table 4. Laterality of the correction through Ponseti's conservative method.

\begin{tabular}{c|c|c}
\hline Left & Right & Bilateral \\
\hline $14(29.8 \%)$ & $12(25.5 \%)$ & $21(44.7 \%)$ \\
\hline
\end{tabular}

Table 5. Number of subjects who obtained correction by the Kite and Ponseti methods, separated by sex.

\begin{tabular}{c|c|c}
\hline Sex & Kite & Ponseti \\
\hline Male & $27(71 \%)$ & $24(51 \%)$ \\
\hline Female & $11(29 \%)$ & $23(49 \%)$ \\
\hline
\end{tabular}

Table 6. Age of patients who obtained satisfactory correction in Kite and Ponseti methods.

\begin{tabular}{c|c|c}
\hline Age & Kite & Ponseti \\
\hline 10-15 days to 6 months & $24(63.2 \%)$ & $37(78.7 \%)$ \\
\hline 6 months to 1 year & $14(36.8 \%)$ & $10(21.27 \%)$ \\
\hline
\end{tabular}


with a fulcrum on the midfoot and support in the tarsometatarsal joint (Lisfranc joint). To correct the varus, hindfoot eversion was performed using wedges and/or cast changes. Forefoot abduction and pronation were forced successively by the manipulations. Correction of the forefoot and hindfoot equinus through progressive dorsiflexion was attempted only after the adductus and inversion deformities had been corrected. However, the Kite method presented several complications such as the "rocker-bottom" deformity, residual cavus feet, navicular subluxation, ligament and capsular stiffness, among other alterations. ${ }^{4}$

According to Ponseti ${ }^{1}$, his method of conservative treatment should be initiated in the first days of life. First, the cavus is corrected, maintaining forefoot supination with the plantar support on the head of the first metatarsus. In the subsequent three or four plaster casts, the adduction and varus deformity are corrected simultaneously, with counter-support on the lateral face of the head of the talus and forefoot abduction. When the abduction is performed, the varus is corrected and only then, the correction of the equinus with a plaster cast in the posterior part of the foot, with a slight dorsiflexion, is initiated. The plaster casts are applied weekly to maintain the degree of correction obtained and to soften the ligaments. Tenotomy is performed when necessary and a Dennis-Brown bar is used.

The Ponseti method ${ }^{1}$, therefore, is still considered a surgical treatment, albeit minimally invasive and was regarded an outpatient procedure by Ponseti ${ }^{1}$ for most patients, regardless of the severity of the deformity. The Kite method ${ }^{4}$, in turn, uses only conservative treatment in mild cases, and the surgical treatment is indicated for more severe deformities. ${ }^{1}$

The Ponseti ${ }^{1}$ and $\mathrm{Kite}^{4}$ methods are the most popular techniques for the correction of ICTEV deformities. Laaveg and Ponseti first described the technique in 1950 and obtained good results, avoiding the need for surgery in $89 \%$ of ICTEV cases. Kite ${ }^{4}$ described his technique in 1932 and obtained a success rate of $90 \%$ in patients who underwent treatment when younger than one year of age. However, other authors have failed to reproduce the same rate of good results; thus, these data have led to doubts about the effective success rate of these conservative methods. ${ }^{5-7}$

The collected sample consisted of 100 children, where 50 children were treated by Kite's conservative method and 50 children were treated by Ponseti's conservative method. Altogether, 127 feet with the ICTEV deformity were treated by Kite and Ponseti's methods. According to Ponseti ${ }^{1}$ and Heber $^{2}$, there is a predominance of ICTEV deformity in males, and in the sample from the present study, $58 \%$ of the children were males, which is consistent with the literature. However, there was predominance of left laterality among patients in the present study, which is in agreement with the literature, while other authors reported the predominance of right deformity and up to $50 \%$ of bilaterality., ${ }^{1,2}$

According to Ponseti ${ }^{1}$, most cases of ICTEV achieve correction after five or six cast changes and often following an achillotenotomy. This technique has shown good results, including for plantigrade and flexible feet, with maintenance of function and absence of pain. The results of this study were in agreement with the literature, whereby most patients ( $94 \%$ of the children of the group treated by the Ponseti method) achieved a satisfactory correction based on Pirani scoring. Thus, a smaller number of cases of ICTEV required an open surgical method to achieve complete correction initiated by the cast changes following the Ponseti method than after the Kite method. Thus, there was a significant difference in efficacy between these two methods in the present study, as only $76 \%$ of patients in the group treated by the Kite method achieved a satisfactory correction $p=0.023(P<0.05)$.

In the Kite group, of the children who achieved successful treatment outcomes according to the Pirani score, $71 \%$ were boys and $29 \%$ were girls. In this same group, $44.7 \%$ of the children achieved a satisfactory correction of the right foot deformity, $42.1 \%$ of the children achieved a satisfactory correction of the left foot deformity, and $13.2 \%$ of the children presented with correction of both feet. In the Ponseti group, of the children who achieved a successful treatment outcome according to the Pirani score, $51 \%$ were boys and $49 \%$ were girls. In this same group, $25.5 \%$ of the children achieved a satisfactory correction of the right foot deformity, $29.8 \%$ achieved a satisfactory correction of the left foot deformity, and $44.7 \%$ of the children presented correction of both feet.

According to Brandão ${ }^{8}$, the earlier conservative treatment is initiated, the more likely it is to be successful. The same was observed in this study, where $63.2 \%$ of the children who achieved correction with the Kite method and $78.7 \%$ of the children with correction by the Ponseti method were within the lowest age range of the study, between 10-15 days and 6 months of age.

The current literature is controversial in providing indications for the choice between $\mathrm{Kite}^{4}$ and Ponseti ${ }^{1}$ conservative treatment methods for ICTEV. However, currently, most orthopedic services prioritize treatment using the Ponseti method due to its superior outcomes. Yet, there are advantages and disadvantages of both treatments that should be taken into consideration when selecting treatment. The advantages of applying Kite's (1932) plaster casting method are the shorter cast reaching the knee, fewer complications involved with its use, and a better manipulation of the patient is permitted. As we are dealing with very poor populations, cast changes can be performed biweekly considering the socio-economic reality of the population, without compromising the effectiveness of the treatment. However, as a disadvantage, the time required for the use of the cast is longer, ranging from 4 to 8 months. ${ }^{1,4,8}$

As for the Kite method, the Ponseti method has advantages such reduced time of cast use and, during the selection of surgery, a minimally invasive technique is considered. Disadvantages of this method are the longer cast applied to the leg, which leads to more complications from its use; its difficult placement, which requires a longer learning curve; and more frequent cast changes, which must be performed weekly. 6,7

Studies comparing conservative treatment without the need for surgical intervention distinguish the two methods in favor of Ponseti. However, it would be more appropriate to compare conservative methods that are followed by a surgical procedure, given that the Ponseti technique is not an exclusively conservative method, and often requires achillotenotomy, although it is considered a minimally invasive outpatient procedure. When this comparison is made using complete treatment, i.e. conservative and surgical intervention, the success rate of the Ponseti method is only 1.27 times higher. ${ }^{7,9,10}$

Sanghvi and Mittal $^{6}$ suggest that the better results obtained in patients treated using the Ponseti Method ${ }^{1}$ may be associated with the minimally invasive procedure in the Achilles tendon. Conversely, these results may also be associated with the failure of the Kite technique in correcting the heel deformity, validating Ponseti's ${ }^{1}$ statement regarding "Kite's error"., 1,6,11

Some limitations to this study must be considered. Although some patients met the inclusion criteria, they had to be excluded from the study due to an allergy to the plaster and the difficulty for some parents to return to the Orthopedics Clinic of the Hospital Infantil Martagão Gesteira for frequent visits, as they resided in remote areas and did not possess the financial resources to cover the costs of transportation.

Although the Kite method ${ }^{4}$ precedes the Ponseti method ${ }^{1}$, the literature reports better outcomes with the latter, which presents a greater degree of correction and avoids open surgery. The achillotenotomy 
procedure considered a minimally invasive procedure according to Ponseti ${ }^{1}$. In this study, the results of the Kite method were not as satisfactory, as a significantly higher number of patients achieved correction of the foot deformity through conservative treatment using the Ponseti method. ${ }^{1,4}$

\section{CONCLUSION}

Based on Pirani scoring, the present study demonstrated that the efficacy of the conservative treatment by the Ponseti method was statistically superior to that of the Kite method for conservative treatment of clubfoot.

AUTHORS' CONTRIBUTIONS: Each author contributed individually and significantly to the development of the manuscript. LCG (0000-0002-9677-8962)* and MLP (0000-0002-2636-6807)*: design, analysis and interpretation of data, writing, critical review, final approval. LRJ (0000-0002-1831-8434)*, MOT (0000-0003-3228-0409)*, FCGF (0000-0003-0780-6595)*, and RJPS (0000-0002-6223-2603)*: analysis and interpretation of data, writing, critical review, final approval. *ORCID (Open Researcher and Contributor ID).

\section{REFERENCES}

1. Laaveg SJ, Ponseti IV. Long-term results of treatment of congenital club foot. J Bone Joint Surg Am. 1980;62(1):23-31.

2. Hebert S, filho TEPB, Xavier R, Junior AGP. Ortopedia e Traumatologia. 4 ed.: Principios e Prática. Porto Alegre: Artmed Editora; 2009. p 1687.

3. Lourenço AF. Pé Torto Congênito. PROATO. Ciclo 1. Módulo 4. Porto Alegre: Artmed Editora; 2005. p 45-69.

4. Kite JH. The Treatment of Congenital Clubfeet: a Study of the Results in Two Hundred Cases. J Am Med Assoc. 1932;99(14):1156-62.

5. Matuszewski $Ł$, Gil L, Karski J. Early results of treatment for congenital clubfoot using the Ponseti method. Eur J Orthop Surg Traumatol. 2012;22(5):403-6.

6. Sanghvi AV, Mittal VK. Conservative management of idiopathic clubfoot: Kite versus Ponseti method. J Orthop Surg (Hong Kong). 2009;17(1):67-71.

7. Rijal R, Shrestha BP, Singh GK, Singh M, Nepal P, Khanal GP, et al. Comparison of Ponseti and Kite's method of treatment for idiopathic clubfoot. Indian J Orthop. 2010;44(2):202-7.

8. Brandão G. Pé Torto Congênito - Revisão e Atualização. Rev Min Ortop E Traumatol. 2011;2:32-40.

9. The classic. Principles involved in the treatment of congenital clubfoot by $\mathrm{J}$. Hiram Kite, M.D. reprinted from J. Bone Joint Surg. 21:595-606, 1939. Clin Orthop Relat Res. 1972;84:4-8.

10. McKay DW. New concept of and approach to clubfoot treatment: section I-principles and morbid anatomy. J Pediatr Orthop. 1982;2(4):347-56.

11. Garcia Filho FC, Dantas J, Tierno G. Tratamento cirúrgico do pé torto congênito pela via de acesso de Cincinnati. Experiência do Hospital Infantil Martagão Gesteira. IV Seminário Internacional de Ortopedia Pediátrica; 1991; Gramado/RS 